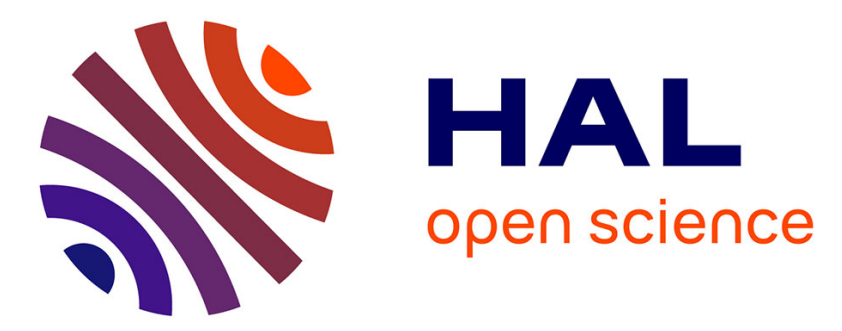

\title{
Optimum machine capabilities for reconfigurable manufacturing systems
}

Eram Asghar, Uzair Khaleeq Uz Zaman, Aamer Ahmed Baqai, Lazhar Homri

\section{To cite this version:}

Eram Asghar, Uzair Khaleeq Uz Zaman, Aamer Ahmed Baqai, Lazhar Homri. Optimum machine capabilities for reconfigurable manufacturing systems. International Journal of Advanced Manufacturing Technology, 2018, 95 (9-12), pp.4397-4417. 10.1007/s00170-017-1560-y · hal-02310461

\section{HAL Id: hal-02310461 \\ https://hal.science/hal-02310461}

Submitted on 10 Oct 2019

HAL is a multi-disciplinary open access archive for the deposit and dissemination of scientific research documents, whether they are published or not. The documents may come from teaching and research institutions in France or abroad, or from public or private research centers.
L'archive ouverte pluridisciplinaire HAL, est destinée au dépôt et à la diffusion de documents scientifiques de niveau recherche, publiés ou non, émanant des établissements d'enseignement et de recherche français ou étrangers, des laboratoires publics ou privés. 


\title{
Optimum Machine Capabilities for Reconfigurable Manufacturing Systems
}

\author{
Eram Asghar ${ }^{1}$, Uzair Khaleeq uz Zaman ${ }^{2 *}$, Aamer Ahmed Baqai ${ }^{3}$, Lazhar Homri ${ }^{4}$ \\ ${ }^{1}$ Ghulam Ishaq Khan Institute of Engineering Sciences and Technology, Pakistan \\ ${ }^{2,4}$ Laboratoire de Conception Fabrication Commande, École nationale supérieure d'arts et \\ métiers, Metz, France \\ ${ }^{3}$ National University of Sciences and Technology, Islamabad, Pakistan \\ * Corresponding author: uzair-khaleeq-uz.zaman@ensam.eu \\ eramasghar@giki.edu.pk \\ aamer.baqai@ceme.nust.edu.pk \\ lazhar.homri@ensam.eu
}

\begin{abstract}
Reconfigurable manufacturing systems constitute a new manufacturing paradigm and are considered the future of manufacturing because of their changeable and flexible nature. In a reconfigurable manufacturing environment, basic modules can be rearranged, interchanged or modified, to adjust the production capacity according to production requirements. Reconfigurable machine tools have modular structure comprising of basic and auxiliary modules that aid in modifying the functionality of a manufacturing system. As the product's design and its manufacturing capabilities are closely related, the manufacturing system is desired to be customizable to cater for all the design changes. Moreover, the performance of a manufacturing system lies in a set of planning and scheduling data incorporated with the machining capabilites keeping in view the market demands. This research work is based on the coevolution of process planning and machine configurations in which optimal machine capabilities are generated through the application of multi-objective genetic algorithms. Furthermore, based on these capabilities, system is tested for reconfiguration in case of production changeovers. Since, in a reconfigurable environment, same machine can be used to perform different tasks depending on the required configuration, the subject research work assigns optimum number of machines by minimizing the machining capabilities to carry out different operations in order to streamline production responses. An algorithm has also been developed and verified on a part family. As a result of the proposed methodology, an optimized reconfigurable framework can be achieved to realize optimal production of a part family. Finally, the proposed methodology was applied on a case study and respective conclusions were drawn.
\end{abstract}

Keywords: Alternative process plans; Multi-objective genetic algorithm; Reconfigurable manufacturing systems; Reconfigurable process plans.

\section{Introduction}

Reconfigurable Manufacturing systems (RMS) have been recommended for the turbulent market conditions because of their flexible and changeable nature. Due to the rapid change in product's design and market demands, there is a need of a system that can adapt the varying requirements more efficiently $[1,2]$. RMS is by default designed around a part family wherein customized flexibility is provided to manufacture all parts within that family. In this perspective a lot of research related to scalability and reconfiguration of RMS has been carried out in literature. Here, scalability is the dynamic characteristic of RMS that allows the system to adjust its capacity according to the market fluctuations and production requirements. Similarly, in reconfiguration, both hardware and software modules are involved which allow quick changeovers in functionality and capacity of the production system [3]. The need of the 
industry today is to have a more reliable and effective system that can offer optimum machining in terms of cost and time. Co-evolution of product design and production system is basically a design for the production of product families and its reconfiguration over several product generations [4]. RMS can be modified physically and logically, i.e., either by changing machine configurations, machine layout, material handling devices, or through suitable routing, scheduling and planning. Throughout the past years, organizations have been in search of the best reconfiguration among a number of presented options to generate economical and distinctive configurations The use of intelligent algorithms have proved their application handy in such situations [5].

This research work is related to reconfiguration of manufacturing system in which optimized reconfigurable framework has been presented to modify the system according to production demands timely with minimum production capabilities. Considering a master part, applying Multi-objective genetic algorithm (MOGA) on its generated process plans and configurations (co-evolution model), gives the global best individual. Moreover, the proposed approach is generic since it generates optimal process plans, and machine configurations on co-evolution paradigm. It also has the ability to cost effectively reconfigure the system. The presented algorithm can further manufacture the part family with minimum production changeover time and optimal machine capabilities. The remainder of the paper has been arranged as follows: Section 2 presents the concerned literature review; Section 3 shows the mathematical formulation; Section 4 presents the proposed methodology along with the application on a case study; Section 5 consists of results and analysis of the case study; and finally, Section 6, discusses the conclusions drawn and future work prospects.

\section{Literature Review}

Active research has been in progress in RMS field for the development of changeability enablers to adjust and rebalance the system configuration depending upon the market requirements. The concept of changeability allows the change enablers to sustain life cycle of a manufacturing system at different levels of any industry. Moreover, scalability is a systematic approach which adds or subtracts from the system's capacity to fulfill the market demand [6]. Reduction in product cost and responsiveness can be observed by customizing first the machining capabilities at product design stage and then the subsequent reuse of these capabilities at reconfiguration stage. It is also necessary to identify the maximum and minimum production capacity values among all configurations [7]. In this section different approaches are discussed in which scalability has been carried out through process planning and machine configurations. Since optimization techniques have gained significant interest by researchers in order to search the global best solution from local solutions, a brief literature survey related to MOGA is also included in this section.

Reconfigurable Process Planning represents important changeability enabler for products and manufacturing systems. Azab and ElMaraghy [8] presented a mathematical model for reconfiguring macro level process plans. To add validity in the previous technique Azab and ElMaraghy [9] applyied genetic algorithm (GA) to get optimized process plan. Most of the process planning issues in literature have been solved using Non-polynomial (NP)-hard approach, since calculus techniques are limited in assuring optimality. Shabaka and ElMaraghy [10] developed a methodology to ensure the generation of feasible process plans using real coded GA for the first time in process planning as it has a large search domain compared to traditional GA. Chaube et al [11] proposed a technique of Non-sorted GA (NSGA) II in which non dominated solutions were sorted and plotted to generate optimal machine configuration and optimal process plan. This integrated approach also required the study of structural configurations of different machining operations. One of the major contributions in configuration selection was carried out by Youssef and ElMaraghy [12]. Since re-configurability is the main factor on which the industrial future depends, the significance of reconfigurable machine tool (RMT) is undeniable. RMT is a modular type of machine tool, having core characteristics like convertibility, integrability and modularity [13]. These characteristics of RMS allow mass customization and rapid response to the product design change. 
Moroever, machine kinematic configurations are generated from the set of functional requirements and process plans in order to design RMTs as stated by Moon and Kota [14]. Another approach, involving the machine configurations to generate the minimum machine capabilities considering the concept of coevolution, was proposed by Shabaka and ElMaraghy [15]. This approach is generic and can be used to generate machine configurations in any manufacturing system since it can be extended in generating the reconfigurable machine structure for part family rather than a single part. The co-evolution theory further reveals that the product, process and production system are interlinked and have a direct impact on each other [4]. In addition, co-evolution of product design and production system is basically a design for the production of product families (having design or feature similarities) and its reconfiguration over several product generations [16]. Reduction in product cost and responsiveness can be observed by customizing the machining capabilities at product design stage and then the reuse of these capabilities at reconfiguration stage. Kumar and Deb [17] carried out an analysis by minimizing weighted function in case of a simultaneous set up and tool change. The results not only gave the optimal solution for each parameter but also optimized the overall effect. Elitist GA methodology was also applied to generate optimal operation sequences in setup planning.

Goyal et al. [18] proposed an approach for optimal assignment of machines in parallel setups through NSGA-II and TOPSIS ranking theory. This approach led to the machine tool reconfiguration by adding or subtracting machine modules going through different performance measures. A quantitative model was also developed for RMS scalability by Wang et al. [7] which calculated the number of reconfigurations based on adjustment gradient. NSGA-II technique has also been used by Bensmaine et al. [19] in the selection of optimal machines from the set of candidate machine configurations. In this research work multi product case with high degree of freedom can be considered as future work and with the idea of co-evolution, the machine configurations can be used for different product designs over and over again preserving the feasibility of the system for a long period of time. Baqai [20] also proposed a methodology to generate reconfigurable process plans and its structural configurations simultaneously considering the precedence, topological and logical constraints. As setup planning plays vital role in the integration of scheduling and process planning, it is closely related to process plan generation and machine selection. Mohapatra et al [21] proposed the method to bridge the gap between scheduling and setup planning by grouping the machining features on the basis of tool approach directions (TAD), adopted NSGA -II and fuzzy set theory to get the pareto optimal solution. In extension to this work, the integration of process planning and scheduling was achieved through an improved version of NSGA-II [22]. Three objective functions; makespan, cost, and idle time were considered on minimizing criteria to obtain the Pareto fronts. A comparative study was also done between NSGA-II, controlled elitist NSGAII and improved controlled elitist NSGA-II. Further, it was observed that the proposed algorithmimproved controlled elitist NSGA-II outperformed other two when efficacy and efficiency were used as comparison parameters. A new methodology was introduced by Azab et al. [23] based on control loop for effective scheduling and planning for system reconfiguration. In this methodology, the inherent characteristics of RMS are analyzed to implement desired changes at system or machine level. Bensmaine et al. [24] proposed a new approach to integrate the process planning and scheduling simultaneously rather than as two separate functions. Considering multi configuration nature of RMTs, a selection index determined the candidate machine which was capable enough to perform certain operations. Recently, Azab and Naderi [25] proposed a methodology in modeling of large problems which included sub family sequencing and parts in each sub family to minimize the maximum completion time using mathematical programming software.

RMS are built to effectively respond to market changes. Although plenty of literature exists on the issues of RMS but a wide scope of study is still required in all fields of RMS. In order to have a reliable and efficient system, nonmonetary product performance measures can also be integrated for balancing production line [26]. To balance the workload and minimize production cost, a methodology combining the capacity control and production planning methods was proposed by Gyulai et al [27]. This 
approach gave the feasible process plans by considering the requirements for capacity in terms of multivariate linear function which is integral part of mathematical model. Moreover, Zhang et al. [28] presented simulation based approach related to remanufacturing through scheduling and process planning to give optimized framework. Considering process routes, the detailed process scheduling was generated through computational experiments using NSGA. Furthermore, Hees and Reinhart [29] discussed scalability planning through modeling simulation technique. The required capacity in terms of machining was attained using integrated model of discrete event simulation and resources' pool functions. One of the drawbacks of this approach was that it required more computational efforts and expertise to get the optimum solution to meet the exact number of machines. Another mathematical approach was proposed by Koren et al. [30] to minimize the total number of machines and maximize system throughput by concurrently reconfiguring and rebalancing the system to match new market demand. This approach offered a set of principles for system design for scalability and was validated for an industrial case. The scalability process planning required simultaneous changing of the system configuration and rebalancing of the related reconfigured system. An optimal scalability-planning problem, which is subject to realistic constraints, was then formulated and solved using GA. This paper also extended the work done by Wang and Koren [3] by applying the mathematical analysis to systems with buffers.

Hassan et al. [31] proposed the methodology for the determination of optimal configuration of multiple part family orders. Machine configuration was selected through NP hard problem but optimization techniques can also be used to reduce computational efforts and ultimately to get improved results. One of the improved algorithms of machine configuration was proposed by Hassan et al. [32] in which Machine Adaptive Retainability Approach was proposed to select process plan by comparing the previously employed process plan with the proposed process plan considering kinematic configurations. Goyal et al. [33] also suggested an approach that focused on creating a Responsive index to measure the responsiveness of RMTs. The responsiveness of a RMT is proposed to be the average of operational capability and machine reconfigurability normalized values because it is quite apparent that both the metrics, i.e., operational capability and machine reconfigurability, directly influence the rapidity with which capacity and functionality requirements can be handled on the machine level.

Conclusively, based on the expansive literature review conducted and the over-arching aim of the research, it was deduced that the application of MOGAs will make the approach more reliable for coevolution of process planning and machine configurations to generate optimal machine capabilities since they preserve best solutions over the generations [34]. Also MOGAs give best solution in process planning problems.

\section{Mathematical formulation}

To carry out production in a part family or when a new part arises and production is to be shifted from one part to another, some major issues faced by decision makers are: are the available machines sufficient for production? which new machines are required? does the setup require reconfiguration? is the available or proposed layout cost effective?, etc. Since the study is about RMS, the production is to be carried out around a part family having operational similarities. The nomenclature involved is given below:

$\mathrm{OP}=$ operation

$\mathrm{NOP}=$ number of operations

$\mathrm{N}=$ number of features to be added

$\mathrm{i}, \mathrm{j}, \mathrm{k}=$ indices for OP number of particular part $[\mathrm{i}, \mathrm{j}, \mathrm{k}, \ldots, \mathrm{NOP}]$ 
$\mathrm{x}, \mathrm{y}=$ indices for $\mathrm{OP}$ number $[\mathrm{x}, \mathrm{y}, \ldots, \mathrm{NOP}]$

$\mathrm{Op}_{\mathrm{x}}=$ operation at ith position, and $\mathrm{Op}_{\mathrm{y}}=$ operation at $\mathrm{jth}$ position in a particular sequence

$\mathrm{TAD}=$ tool approach direction for each operation

Designing a manufacturing system consists of two different tasks: the first task consists of determining the set of machines to be involved in the production process, while the second task concerns the definition of the selected machines layout. Considering a multi-product case, each machining feature of given part is assigned a serial number and a suitable machining operation is identified on the basis of machining and geometrical requirements and the TAD matrix capable of producing each operation depending on machines visibility. The design variables involved which have a direct impact on the objective function [described later in Section 4 (see Eq. 4) in detail] are given as follows:

\section{Design Variables}

A. Operation sequence (OS):

$O S=\left\{O p_{1}, \mathrm{O} p_{2}, \mathrm{O} p_{3} \ldots \mathrm{O} p_{n o p}\right\}$

where $\mathrm{O} p_{i}$ is the operation taking the $i^{\text {th }}$ position in the sequence.

B. Tool Approach Directions (TADs)

$T A D s=\left\{\operatorname{tad}_{1}, \operatorname{tad}_{2}, \operatorname{tad}_{3}, \ldots \ldots . \operatorname{tad}_{N O P}\right\}$,

where $\operatorname{tad}_{i}$ is the TAD assigned to operation $O p_{i}$.

C. Precedence Group Matrix (PGMS):

Operations are grouped based on precedence and technological constraints.

$O p(x, y)$ is the precedence between $O p_{x}$ and $O p_{y}$

Tool change, setup change and part rotation matrices are used as input to find the optimal process plan and to select a set of machines that are able to achieve all the necessary operations to accomplish the desired product while minimizing time and costs in terms of tool and configuration changeovers incurred during the production. Suppose $O \mathrm{p}_{\mathrm{x}}$ and $\mathrm{Op} \mathrm{p}_{\mathrm{y}}$ are the randomly generated sequence of operations, they will go through tool change, setup change and part rotation check. For this, the data in matrix form is required. If the corresponding value against the operations in matrix is 1 , it means there is change in tool, setup and part rotation between operations, and 0 means otherwise. Each machine comprises of various modules performing as different tools and providing different operation of parts. Configuration changeover depends upon the machine's visibility for that particular operation. Depending on the required product design, these modules can be added or removed. The mathematical formulation for the inputs and the constraints involved are given below:

Inputs

Mtool $\left[O p_{i, j}^{N}\right]\left[O p_{i, j}^{N}\right]=$ Matrix showing the tool change between operations

$\operatorname{Msetup}\left[O p_{i, j}^{N}\right]\left[O p_{i, j}^{N}\right]=$ Matrix showing the post / setup change between operations

$\operatorname{Mrot}\left[O p_{i, j}^{N}\right]\left[O p_{i, j}^{N}\right]=$ Matrix showing the part rotation between operations

A. Tool Change:

$$
\text { TOC }=\sum_{i=1}^{N O P-1}[1-(1-\operatorname{Mtool}(O p(i), O p(i+1))]
$$




$$
\operatorname{Mtool}(x, y)= \begin{cases}1, & x \neq y \\ 0, & x=y\end{cases}
$$

B. Post / Setup Change:

$$
\begin{aligned}
& \operatorname{Setup}_{i}=\sum_{i=1}^{N O P-1}[1-(1-M \operatorname{setup}(O p(i), O p(i+1))] \\
& \operatorname{Msetup}(x, y)= \begin{cases}1, & x \neq y \\
0, & x=y\end{cases}
\end{aligned}
$$

C. Part Rotation:

$$
\begin{aligned}
& \operatorname{Rot}_{i}=\sum_{i=1}^{N O P-1}[1-(1-\operatorname{Mrot}(O p(i), O p(i+1))] \\
& \operatorname{Mrot}(x, y)= \begin{cases}1, x \neq y \\
0, & x=y\end{cases}
\end{aligned}
$$

\section{Constraints}

A. Precedence Constraints for operations:

If $O p_{x}$ is performed before $O p_{y}, \operatorname{Prced}\left(O p_{x}, O p_{y}\right)=1$

If $O p_{y}$ is performed before $O p_{x}, \operatorname{Prced}\left(O p_{x}, O p_{y}\right)=-1$

If $O p_{x}=O p_{y}, \operatorname{Prced}\left(O p_{x}, O p_{y}\right)=0$

B. Operations Assigned Only Once:

$O p_{i, j} \neq O p_{i, k} \quad \forall j \neq k \quad$ where $j, k \in N O P$

\section{Proposed Methodology and Case Study}

The proposed solution to the identified problem is based on co-evolution model. Fig. 1 demonstrates the output and the inputs of the proposed methodology. Operational data, precedence constraints, and technological constraints are the inputs required to produce alternative process plans (APPs). Machine configurations are obtained from the combinations of TADs and applying algorithm of system reconfiguration gives minimum machine capabilities. As a result of this framework, optimum machines are obtained for a part family considering reconfigurable setup. Furthermore, the proposed methodology has been categorized into two stages. In the first stage, the algorithm for generating and optimizing APPs and machine configurations, is presented while in the second stage, best fit solutions obtained for master part from GA are compared with the APPs and configurations of other parts to get minimum machining requirements.

\section{\{Please insert Fig. 1 about here\}}

Best possible machines are assigned to all the parts belonging to same part family on the basis of minimum machine capabilities obtained by reconfiguring the setup. The comparison is carried out on the basis of the minimum difference between the machine configurations of the new part and the optimized configurations of master part available. Moreover, machine configurations are generated corresponding to the generated process plans considering tool orientation for a particular operation. Three parts are considered for the validation of proposed methodology since they belong to the same part family and are similar on the basis of operational similarity: Part A - Couvercle De Vileberequin (CDV - shaft cover); Part B - Corps de Pompe a Huile moteur (CPHC - engine oil pump); and Part C - Couvericle d'Abrdre 
(CAI - intermediate shaft cover). The specifications for these parts are shown in Annexure. Part A is considered as the master part as shown in Fig. 2. Parts B and C are shown in Fig. 3 and Fig. 4, respectively.

\{Please insert Fig. 2 about here\}

\{Please insert Fig. 3 about here\}

\{Please insert Fig. 4 about here\}

The proposed reconfiguration framework is shown in Fig. 5 which is explained in the following sub sections. The implementation of the framework starts from process planning algorithm which has been applied on all of the three parts.

\{Please insert Fig. 5 about here\}

\subsection{Co-evolution of Process Planning and Machine Configuration}

The inputs of the algorithm are the set of operations, precedence relationship(s), constraints, tool change(s), setup change(s), part rotation(s) and TAD matrix. The tool change, setup change and part rotation matrix for Part A are shown in Annexure for more insight. APPs are generated from the proposed algorithm considering specific constraints such as precedence, datum, geometrical, and technological constraints [35]. Precedence constraints are taken into account to get feasible process plans since they determine which operation needs to be performed before the other one to assist the planner in taking the scheduling decision. Datum constraints account for those operations which can be performed on the same machine with the same setup. Geometrical constraints are used for reference purposes, while technological constraints are incorporated where any particular operation is inevitable to be performed after a specific machining operation. These constraints are to be satisfied while manufacturing any product. In the proposed algorithm of process planning, the precedence check is added to verify the precedence and technological constraints. The major step is the grouping of operations on the basis of ranking. It gives pre- and post- operations of a particular part as shown in Tab. 1:

\{Please insert Tab. 1 about here

As the optimal process plan and its corresponding configuration is required for the master part (Part A), the application of MOGA gave the optimal solution from local solutions. The optimal search was further carried out by applying the classical MOGA which is referred to as the weighted GA (WGA) in literature. In WGA, optimal solutions can be controlled and the preference to any objective can be given by increasing its weight. However, it is worthy to note that the solutions having equal weights of the objectives offer least conflict. The advantage of this technique is that it controls the dominance of one objective over the other and converges the system towards pareto optimum solution. Real coded GA has also been used to get an optimized process plan and to ensure that the generated process plan conforms to the subjected precedence constraints. A comparison between two optimization approaches, i.e., WGA and NSGA-II was carried out in previous work [36]. The flow chart for the WGA is shown in Fig. 6.

\{Please insert Fig. 6 about here\}

A machine's structural configuration is generated on the basis of machine's visibility to generate any particular feature of the part family. Different combinations of TADs help in finding out the appropriate combination for a particular process plan to carry out production with minimum capabilities. In Tab. 2, different combinations of TAD for Part A are shown against each operation along with precedence groups. For example, Operation 1 (Op1) can be performed from $X, Y$ and $-Z$ directions, but the objective is to find the optimum direction. If $O p 1$ is performed from $+v e X$ direction of tool, $O p 2$ with $+v e Y$ direction and $O p 7$ from $-v e Z$ direction, a 5-axis machine will be required to carry out these 
operations. On the other hand, a single 3-axis machine will be required if all of the three operations are performed from $-v e Z$ TAD. Therefore, different combinations of TADs help in finding out which combination is best suited for a particular process plan to carry out production with minimum capabilities. And for the same reason, all combinations are considered in analysis of the case study parts.

\section{\{Please insert Tab. 2 about here\}}

Fitness evaluation of the whole population generated was based on the minimization of the fitness criteria (objective function) as shown in Eq. 4:

$f=\min \left[\sum_{i=1}^{n} T_{i} w 1+\sum_{i=1}^{n} S_{i} w 2+\sum_{i=1}^{n} R_{i} w 3+\sum_{i=1}^{n} d o f_{i} w 4\right]$

where $T_{i}=$ tool change array, $S_{i}=$ setup change array, $R_{i}=$ part rotation array, $d o f_{i}=$ spindle degree of freedom, $n=$ total number of alternative process plans, and $w 1-4=$ weightages of each parameter considered. The process gave best fit process plans along with their corresponding kinematic configurations. Machine configurations are considered in the next stage of the methodology.

\subsection{System Reconfiguration}

To produce parts within the same part family, there is a need of certain criteria based on which the production could be switched from one part to another. The proposed algorithm shown in Fig. 7 is used to reconfigure the setup according to the production requirements. For part A, optimal plan and its optimal machine configuration are obtained and then compared with all possible APPs and configurations of other parts belonging to the same family. 'Counter' saves the minimum difference in configurations of both parts. If the minimum values in 'counter' are more than 1, minimum setup is checked for, otherwise the optimized process plan having minimum change in configuration is extracted. Modification of setup is carried out based on the information obtained by applying this algorithm. The results of this algorithm are illustrated later in next section.

\{Please insert Fig. 7 about here

The assignment of operations on machines is carried out in three steps. First TAD and the type of tool required to carry out the operation is identified which is the machine kinematic configuration. In the second step, among the available machines, the set of machines capable of performing that particular operation are identified. This is done by identifying the TAD offered by the machine and the available tools. Finally, the machines and the appropriate configuration are assigned to the particular operation of the sub-part.

Machines are assigned to manufacture different parts belonging to the same part family on the basis of information obtained from the system reconfiguration algorithm (see Fig. 8). 3-axis, 4-axis and 5axis machines are assigned considering machine configuration required to produce a particular feature.

\{Please insert Fig. 8 about here\}

The developed methodology was applied on Parts A, B and C. As described earlier, part A was taken as master part and by the application of above stated algorithm, the system was reconfigured to produce parts $\mathrm{B}$ and $\mathrm{C}$ with optimum capabilities.

\section{Results and Analysis}

This section presents the optimized assignment of machines to the operations using optimum machine capabilities. The optimized process plan and kinematic configuration of part A was obtained 
using Eq. 4. The generation vs. fitness graph (see Fig. 9) shows the convergence of system towards minimum fitness. Over the generations of 500, fitness converges upto 275 for population size of 50 .

\{Please insert Fig. 9 about here

The optimized process plan and its machine configuration (Spindle rotates clockwise from its default position at an angle of $90^{\circ}$ about $\mathrm{X}$-axis) for Part $\mathrm{A}$ are obtained through MOGA and shown in Tab. 3. The application of reconfiguration algorithm gave the optimal machining capabilities for parts $\mathrm{B}$ and C. The optimal process plans for part B and part $\mathrm{C}$ are given in Tab. 4 and Tab. 5. The purpose of RMS also satisfies here which is to provide the exact capacity required. As the optimum machine configurations are obtained for each operation, the machines can be assigned according these capabilities and process planning parameters. The machines assigned to the parts A, B and C are mentioned in Tab. 6 .

\{Please insert Tab. 3 about here

\{Please insert Tab. 4 about here\}

\{Please insert Tab. 5 about here\}

\{Please insert Tab. 6 about here

Graphical representation of machine assignment is given in Fig. 10. The re-configurable setup as shown in Fig. 11 gives the minimum machine capabilities required for manufacturing parts within the part family.

\{Please insert Fig. 10 about here\}

\{Please insert Fig. 11 about here\}

\section{Conclusions and Future Suggestions}

The concept of reconfigurability in manufacturing system has gained significant importance. To respond to the high frequency variations and to stay competitive, industrial requirement is to adapt production system efficiently. The concept of co-evolution was taken into consideration in this paper. The machine configurations were generated for different features of a part family corresponding to that of generated process plans. This research work is concerned with the development of an integrated approach for modifying the setup according to the variations in product design. By the application of WGA on coevolution model, the system yielded global optimal. Furthermore, the framework included optimum process plans, optimum machines' kinematic configurations, and reconfiguration changeability extent. Reconfigurable process planning represents important changeability enablers for product and manufacturing system evolution. It cost effectively manages the change in product and modifies the system accordingly. In the proposed approach, the extent of reconfiguration was measured which formed the basis for defining the process plans and machine configurations of other parts. This approach also helped in carrying out production with optimized capabilities. In case of random market demands and design variations the proposed approach is reliable as it determines the minimum and optimal required capabilities to the corresponding operations of a part. Moreover, the presented algorithm can manufacture the part family with minimum production changeover time and optimal machine capabilities. This work can be extended for multiple and parallel setups. Extension of the same algorithm by increasing the number of parts will add versatility in the system. Different manufacturing costs, time and machining specifications like spindle speed, depth of cut, etc., can also be considered as part of the future work.

\section{Annexure}

\{Please insert Fig. 12 about here\}

\{Please insert Tab. 7 about here\}

\{Please insert Fig. 13 about here\} 
\{Please insert Tab. 8 about here\}

\{Please insert Fig. 14 about here\}

\{Please insert Tab. 9 about here\}

\{Please insert Tab. 10 about here\}

\{Please insert Tab. 11 about here\}

\{Please insert Tab. 12 about here\}

\section{References:}

[1] Meghrabi MG, Ulsoy AG, Koren Y (2000) Reconfigurable Manufacturing System: Key to future manufacturing. Journal of Intelligent Manufacturing 11: 403-419.

[2] Meghrabi MG, Ulsoy AG, Koren Y, Heytler P (2002) Trends and perspectives in flexible and reconfigurable manufacturing system. Journal of Intelligent Manufacturing 13: 135-146.

[3] Wang W, Koren Y (2012) Scalability Planning for reconfigurable manufacturing system. Journal of Manufacturing Systems 31: 83-91.

[4] Tolio T, Ceglarek D, ElMaraghy HA, Fischer A, Hu SJ, Laperriere L, Newman ST (2010) SPECIES-Coevolution of products, processes and production systems. CIRP Annuals- Manufacturing Technology 59(2): 672693.

[5] Lateef-Ur-Rehman AUR (2012) Manufacturing configuration selection using multicriteria decision tool. International Journal of Advanced Manufacturing Technology 65: 625-639.

[6] Wiendahl HP, ElMaraghy HA, Nyhuis P, Zah MF, Wiendahl HH, Duffie N, Brieke M (2007) Changeable Manufacturing-classification, design and operation. CIRP Annals-Manufacturing Technology 56(2): 783-809.

[7] Wang GX, Huang SH, Yan Y, Du JJ (2016) Reconfiguration schemes evaluation based on preference ranking of key characteristics of reconfigurable manufacturing systems. International Journal of Advanced Manufacturing Technology 89: 2231-2249.

[8] Azab A, ElMaraghy HA (2007) Mathematical Modeling for reconfigurable process planning. CIRP Annals Manufacturing Technology 56(1): 467-472.

[9] Azab A, ElMaraghy HA (2007) Sequential process planning: A hybrid optimal macro level approach. Journal of Manufacturing Systems 26(3): 147-160.

[10] Shabaka AI, ElMaraghy HA (2008) A model for generating optimal process plan in RMS. International Journal of Computer Integrated Manufacturing 21(2): 180-194.

[11] Chaube A, Benyoucef L, Tiwari M (2012) An adapted NSGA-2 algorithm based dynamic process plan generation for a reconfigurable manufacturing system. Journal of Intelligent Manufacturing 23(4): 1141-1155.

[12] Youssef AM, ElMaraghy HA (2007) Optimal configuration selection for reconfigurable manufacturing systems. International Journal of Manufacturing Systems 19(2): 67-106.

[13] Aboufazili N (2012) Reconfigurable Machine Tool and measuring reconfigurable for design evaluation. The Royal Institute of Technology, Sweden.

[14] Moon YM, Kota S (2002) Design of reconfigurable machine tools. Journal of Manufacturing Science and Engineering 124(2): 480-483.

[15] Shabaka AI, ElMaraghy HA (2007) Generation of machine configurations based on product features. International Journal of Computer Integrated Manufacturing 20(4): 355-369. 
[16] Bryan A, Ko J, Hu SJ, Koren Y (2007) Co-evolution of product families and assembly systems. CIRP Annals Manufacturing Technology 56(1): 41-44.

[17] Kumar C, Deb S (2012) Generation of Optimal Sequence of machining operations in set up planning by genetic algorithms. Journal of Advance Manufacturing Systems 11(1), 67-80.

[18] Goyal KK, Jain PK, Jain M (2012) Optimal configuration selection for reconfigurable manufacturing system using NSGA II and TOPOSIS. International Journal of Production Research 50(15): 4175-4191.

[19] Bensmaine A, Dahane M, Benyoucef L (2013) A non-dominated sorting genetic algorithm based approach for optimal machines selection in reconfigurable manufacturing environment. Computers and Industrial Engineering 66(3): 519-524.

[20] Baqai A (2010) Co-conception des processus d"usinage et des configurations cinematiques decun systeme de production reconfigurable. (Doctoral dissertation, Arts et Metiers Paris Tech), France, NNT: 2010-ENAM- 0010.

[21] Mohapatra P, Benyoucef L, Tiwari MK (2013) Integration of process planning and scheduling through adaptive setup planning: a multi-objective approach. International Journal of Production Research 51(23-24): 7190 -7208.

[22] Mohapatra P, Nayak A, Kumar SK, Tiwari MK (2015) Multi-objective process planning and scheduling using controlled elitist non-dominated sorting genetic algorithm. International Journal of Production Research 53(6): 1712-1735.

[23] Azab A, ElMaraghy H, Nyhuis P, Pachow-Frauenhofer J, Schmidt M (2013) Mechanics of change: A framework to reconfigure manufacturing system. CIRP Journal of Manufacturing Science and Technology 6(2): 110-119.

[24] Bensmaine A, Dahane M, Benyoucef L (2014) A new heuristic for integrated process planning and scheduling in reconfigurable manufacturing system. International Journal of Production Research 52(12): 3583-3594.

[25] Azab A, Naderi B (2015) Modelling the problem of production scheduling for reconfigurable manufacturing systems. CIRP Conference on Intelligent Computation in Manufacturing Engineering 33: 76-80.

[26] Xie N, Li A, Xue W (2012) Cooperative optimization of reconfigurable machine tool configurations and production process plan. Chinese Journal of Mechanical Engineering 25(5): 982-989.

[27] Gyulai D, Kadar B, Monosotori L (2015) Robust production planning and capacity control for flexible assembly lines. IFAC-PapersONLine 48(3): 2312-2317.

[28] Zhang R, Ong SK, Nee AY (2015) A simulation-based genetic algorithm approach for remanufacturing process planning and scheduling. Applied Soft Computing 37: 521- 532.

[29] Hees A, Reinhart G (2015) Approach for production planning in reconfigurable manufacturing systems. 9th CIRP conference on intelligent computing 33: 70-75.

[30] Koren Y, Wang W, Gu X (2017) Value creation through design for scalability of reconfigurable manufacturing systems. International Journal of Production Research 55(5): 1227-1242.

[31] Hassan F, Jain PK, Kumar D (2013) Optimum configuration selection in reconfigurable manufacturing system involving multiple part families. Opsearch 51(2): 297-311.

[32] Hassan SM, Baqai A (2013) An approach for the Selection of Process Plans based on Part Family Changes. Advances in Sustainable and Competitive Manufacturing Systems: 65-77. 
[33] Goyal KK, Jain PK, Jain M (2013) A novel methodology to measure the responsiveness of RMTs in reconfigurable manufacturing system. Journal of Manufacturing Systems 32: 724-730.

[34] Sastry K, Goldberg D, Kendall G (2014) Genetic Algorithms. Search Methodologies: 93-117.

[35] Zahid T, Baqai AA (2013) Muti criteria optimization of process plans for reconfigurable manufacturing system: an evolutionary approach. International Mechanical Engineering Congress and Exposition, (pp. V02BT02A045V02BT02A045). American Society of Mechanical Engineers.

[36] Asghar E, Baqai AA, Zaman UKU (2015) Performance of NSGA-II and WGA in macro level process planning considering reconfigurable manufacturing system. Proceedings of $25^{\text {th }}$ International Conference on Flexible Automation and Intelligent Manufacturing 2: 320-327. 